\title{
Is There a Stigma towards Mental Illness among Medical Students? - A Systematic Review of the 1997-2018 Literature
}

\author{
Ruth Gervas ${ }^{1}$, Gloria Bueno ${ }^{2}$, Llanyra Garcia-Ullan³, Rafaela de La Mata4 ${ }^{4}$, Carlos Roncero 5
}

${ }^{1}$ Department of Medicine. Psychiatry Area (University of Salamanca) Salamanca, Spain; Associate Investigator, IBSAL

(Institute of Biomedicine of Salamanca) University of Salamanca Health Care Complex; Spain. ${ }^{2}$ Department of Medicine. Psychiatry Area (University of Salamanca), Salamanca, Spain. Associate Investigator, IBSAL (Institute of Biomedicine of Salamanca) University of Salamanca Health Care Complex; Spain. ${ }^{3}$ Department of Medicine. Psychiatry Area (University of Salamanca), Salamanca, Spain. Psychiatrist of Psychiatry Service, University of Salamanca Health Care Complex; Spain. Associate Investigator, IBSAL (Institute of Biomedicine of Salamanca), University of Salamanca Health Care Complex; Spain. ${ }^{4}$ Psychiatrist of Psychiatry Service, University of Salamanca Health Care Complex; Spain. ${ }^{5}$ Department of Medicine. Psychiatry Area (University of Salamanca), Salamanca, Spain. Head of Psychiatry Service, University of Salamanca Health Care Complex; Spain. Associate Investigator, IBSAL (Institute of Biomedicine of Salamanca) University of Salamanca Health Care Complex; Spain.

\section{ABSTRACT}

\section{BACKGROUND}

The stigma associated with mental illness is a global public health problem ${ }^{3}$, having worse consequences than the disorders themselves ${ }^{4}$. The objective of this study is to review the literature on the stigma towards mental illness in medical students and know about its presence.

\section{METHODS}

Following the PRISMA ${ }^{9}$ methodology, a systematic review is carried out in PubMed, Web of Science (WOS) and Cochrane Library. We proceed to the reading of the abstracts of a total of 67 manuscripts, 38 of which are excluded because they do not comply with the parameters that are the object of the study. Additionally, 9 relevant articles of associated searches are reviewed.

\section{RESULTS}

A total of 38 manuscripts containing a participation of 18,808 medical students are evaluated. The publications come from 20 countries worldwide, without a representative predominance of any of them, led by Great Britain and Canada. $87 \%$ of the publications are concentrated in the last 8 years, showing the increase and continued presence of research.

\section{CONCLUSIONS}

The existence of stigma towards mental illness among the target population is corroborated in $97 \%$ of the literature. This is a heterogeneous field of study with few studies with large sample sizes. More research is needed to identify interventions which will produce a long-term change in behaviour to reduce stigma among medical students.

\section{KEY WORDS}

Mental Health, Social Stigma, Students, Medical
Corresponding Author:

Dr. Ruth Gervás,

Medicine University of Salamanca,

Department of Medicine, Psychiatry Area, Paseo de la Universidad de Coimbra $S / N$,

37007, Salamanca, Spain.

E-mail: ruthgervas@usal.es

DOI: $10.14260 /$ jemds/2020/67

Financial or Other Competing Interests: None.

How to Cite This Article:

Gervas R, Bueno G, Garcia-Ullan L, et al. Is there a stigma towards mental illness among medical students? - a systematic review of the 1997-2018 literature. J. Evolution Med. Dent. Sci. 2020;9(05):299303, DOI: $10.14260 / \mathrm{jemds} / 2020 / 67$

Submission 05-11-2019,

Peer Review 14-01-2020,

Acceptance 20-01-2020,

Published 03-02-2020. 


\section{BACKGROUND}

Stigma is described as an undesirable and unpleasant attribute that sets the stigmatized person apart from other members of the community that the person should belong to, according to Ervin Goffman ${ }^{1}$ (1963). In the field of mental health, it is considered a multidimensional construct whose form of presentation may vary depending on the context and the relationships that take place in it. Stigma associated with mental illness is considered a global public health issue. ${ }^{2}$ It has been said that stigma and discrimination ${ }^{3}$ related to mental illness have worse consequences than the disorders themselves. The stigma does not only increase the burden of the disease by acting as a barrier for the search for help, but also perpetuates itself as future generations of medical practitioners ${ }^{4}$ assimilate the stereotypes of medical culture, which has a negative impact on the quality of patient care.

Therefore, the stigma of mental illness among medical students is a common concern that has far-reaching negative consequences. 5 Medical students, who are considered a specific category of health professionals, are an important group that needs to be oriented with regard to their attitudes towards people with mental illness 6 . These attitudes are more malleable during the first years ${ }^{7}$ of their training, when they come closer to the psychosocial causal model, and become harder to approach as their training continues and they begin their residency ${ }^{8}$, when they veer towards the biomedical model.

As future doctors, they will be influential in shaping the culture of medicine, and their responses (Or the lack of them) to different stigmatizing behaviours or attitudes will create a model of what doctors consider inappropriate conduct. ${ }^{9}$ The population of medical students and doctors is exposed to a greater risk of exhaustion and addictions than the general population, but they are reluctant to seek help due to the major stigma associated to it. ${ }^{10}$ Part of this reluctance can also be derived from the possible negative consequences in the career of a doctor or a future doctor if they disclose having or having had a mental disorder, because medicine is a regulated profession in which disclosure of a mental disorder may limit their capacity to practice. In spite of the perception that medical students and doctors must be "invincible," 11 mental health disorders are common in this population. ${ }^{8}$ For this reason, it is important to assess the situation of the stigma towards mental disorders and to know about the potential interventions that can be made. The objective is to carry out an international systematic review of the literature on the stigma of mental illness among medical students over the last 21 years.

\section{METHODS}

In line with the PRISMA methodology (Preferred Reporting Items for Systematic reviews and Meta-Analyses),12 a systematic review of the literature was carried out on the databases PubMed, Web of Science (WOS) and Cochrane Database of Systematic Reviews* stigma health mental, medical students in All Text ', Cochrane Library. According to the premises for the identification of relevant studies from several different sources, they were selected for their inclusion and for an adequate data collection and synthesis.

The search included the following terms: (C"Social Stigma"[MeSH Terms] or ("social"[all Fields] and "stigma"[All Fields]) or "social stigma"[All Fields] or "stigma"[all Fields]) AND ("mental health"[MeSH Terms] or ("Mental"[All Fields] and "health"[All Fields]) or "mental health"[All Fields]) and ("Students, medical" [MeSH Terms] or ("Students"[All Fields] and "medical"[all Fields]) OR "medical students"[All Fields] OR ("medical"[All Fields] and "students"[All Fields]))) and (Review[ptyp] and ("1997/01/01"[PDAT]: "2018/12/31" [PDAT]) AND "humans"[MeSH Terms]).

In WOS the search strategy was Topic: (stigma*) and Topic: (Mental Health*) and TOPIC: (Medical Students*), filter: Open Access: (Open Access) And Open Access: (Open Access) and Research Fields: (Science Technology Or Social Sciences) AND [excluding] Databases: (CCC or Scielo) and Topic: (Stigma). Timespan 1997-2018, Search language $=$ Auto Regarding the inclusion criteria, the studies must: (i) include a sample with university medical students, regardless of its size, (ii) come from any faculty of medicine worldwide, (iii) research the stigma towards absent or present mental illness. After the search, 67 documents were assessed and reviewed through a reading of the corresponding abstracts. A total of 38 texts were excluded because they did not meet the parameters of the study. Additionally, 9 manuscripts obtained from the references in the articles were reviewed. (See Figure 1. Flow diagram). After selecting the literature, the parameters of the study were registered: year of publication, country of publication, number of medical students who participated in each study and the different kinds of interventions to reduce it.

\section{RESULTS}

In total, 38 publications were assessed which had a global participation of 18,808 medical students. 6 of them were systematic reviews and 32 were articles that contain 128 studies. $97 \%$ of the reviewed literature confirms the existence of a stigma towards mental illness among medical students. With regard to their geographic location, the studies are distributed among 20 countries worldwide. With regard to the continental (Geographic/Cultural) distribution, Europe ${ }^{13,14,7}$ ranks first (37\%), followed by Asia $15,16,6(29 \%)$ and North America (18\%). (Figure 2. Distribution number publication /continents). (Figure 3. Annual distribution of publications). Regarding the distribution in years, $87 \%$ of the studies had been published over the last 8 years, and we observed a constant increase in the amount of publications. In $95 \%$ of them, the intervention methodologies to reduce the stigma had positive results, with the only exceptions of Iran, ${ }^{8}$ with two randomized clerkships with patient exposure, and Spain, ${ }^{17}$ where no association was observed. Didactic teaching 18 and self-directed learning ${ }^{19}$ showed an improvement in the knowledge of and attitudes towards depression, ${ }^{20}$ education through exposure ${ }^{12,21}$ had a strong anti-stigma effect; and when it was included in the curriculum, ${ }^{22}$ it reduced the stigma of mental illness and increased confidence among students. ${ }^{5,21}$ 

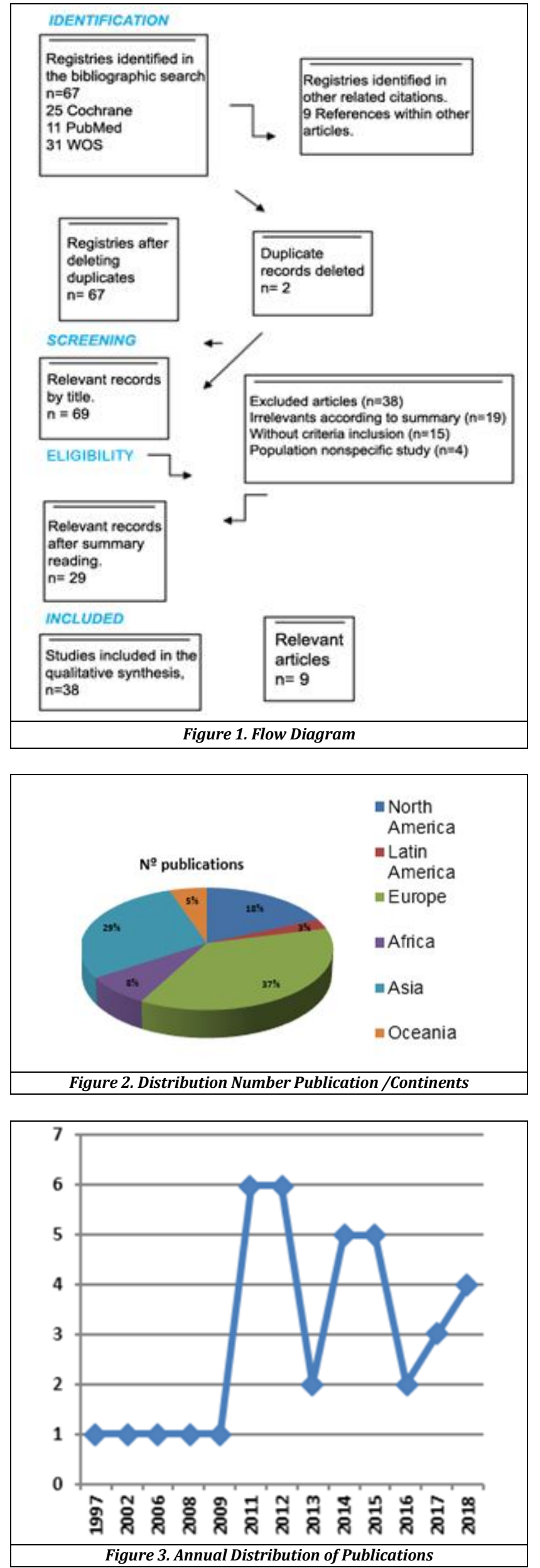

\section{DISCUSSION}

This study examines the stigma towards mental illness among medical students. The presence of stigma is confirmed in $97 \%$ of the articles reviewed. This is a heterogeneous field of research with few solid study designs with large sample sizes. The studies were published, in order of frequency, in Europe (14), Asia (11), and North America (7), plus a few contributions in Africa (3), Oceania (2) and Latin America (1). The rank is different if we consider the number of students who participated in the studies, with Asia ${ }^{15,23,24,16,17}$ in the first position (6492), followed by Europe ${ }^{13,14,7}$ (5730), North America (2887) and Oceania ${ }^{24}$ (2521), and finally by Africa ${ }^{23,25}$ and Latin America (398 and 21 students, respectively). Little research is found from low and middle income countries ${ }^{3}$, in spite of the fact that these are the countries in which medical students endorse more stigma attitudes. The studies come from 20 different countries, with no clear predominance, which is a clear sign of the magnitude of the problem of stigma, which is independent from contextual, cultural or sociodemographic differences.

According to Sartorius, "stigma is the most significant obstacle to the development of mental health care." 26 This combined with the population of "medical students" as future healthcare professional whose perspectives and behavior will play a significant role in future social attitudes towards people affected by mental illness, shows the need for comprehensive interventions and changes.

Among healthcare professionals, more negative attitudes are observed in non-psychiatric doctors (In spite of their medical bias $)^{11}$ than in psychiatrists. Studies in countries such as Spain, ${ }^{27}$ Oman $^{27}$ and Canada $^{27}$ reported that medical students, nursing students and non-psychiatric mental health professionals share the beliefs of the general public in their respective countries.

No differences regarding attitudes towards stigma were observed between medical students and social workers ${ }^{10}$, although the stigma was greater than what was observed among undergraduate students (with huge gaps in their knowledge of psychiatry and treatment) ${ }^{28}$ or among psychiatrists, ${ }^{29}$ and lower than what was observed among nursing students. ${ }^{30}$ With regard to the different pathologies, greater stigma was observed towards schizophrenia than towards depression among medical students. ${ }^{31}$

One of the strengths of our study is the fact that it reports the stigma towards people with mental illness among medical students and it carries out a systematic review with findings in the entire world, without language restrictions, and it finds a significant effectiveness of $95 \%$ in anti-stigma interventions. Different types of strategies may be required for different types of students. ${ }^{32}$

Limitations in our study include small samples with large variability between different locations, which makes it difficult to generalize the results. All the outcomes are considered equally. No clear expression has been found of the prognostic factors for stigmatizing attitudes, and there is a potential causality in the multidimensionality of the construct or in the contextual cultural or socio-political variables at any given time. 33 


\section{CONCLUSIONS}

There is a stigma among medical students towards mental illness. We observed a lack of evidence for interventions, particularly in the long term. ${ }^{12}$ Further work is required in this area, and more studies are needed to determine what interventions ${ }^{31}$ may be adequate to achieve the much-coveted stable reduction of the stigma, if that is at all possible. Only then can the stigma be reduced through a large-scale intervention that is multidisciplinary, feasible and beneficial for all the people who live with mental illness ${ }^{34}$ by introducing a holistic approach in faculties of medicine. ${ }^{35}$

\section{REFERENCES}

[1] Goffman E. Stigma: notes on the management of spoiled identity. New Jersey, USA: Englewood Cliffs, N.J., Prentice Hall 1963.

[2] Griffiths KM, Carron-Arthur B, Parsons A, et al. Effectiveness of programs for reducing the stigma associated with mental disorders. A meta-analysis of randomized controlled trials. World Psychiatry 2014;13(2):161-75.

[3] Thornicroft G, Rose D, Kassam A, et al. Stigma: ignorance, prejudice or discrimination? British Journal of Psychiatry 2007;190:192-3.

[4] Suwalska J, Suwalska A, Neumann-Podczaska A, et al. Medical students and stigma of depression. Part 1. Stigmatization of patients. Psychiatria Polska 2017;51(3):495-502.

[5] Papish A, Kassam A, Modgill G, et al. Reducing the stigma of mental illness in undergraduate medical education: a randomized controlled trial. BMC Medical Education 2013;13:141.

[6] Sireesha SR, Lanka UVR, Reddy JM, et al. A cross-sectional and comparative study of stigma in undergraduate medical students towards mentally ill patients. Journal of Evolution of Medical and Dental Sciences 2015;4(94):15963-70.

[7] Korszun A, Dinos S, Ahmed K, et al. Medical student attitudes about mental illness: does medical-school education reduce stigma? Acad Psychiatry 2012;36(3):197-204.

[8] Amini H, Shoar S, Tabatabaee M, et al. The effect of clinical exposure to patients on medical students' attitude towards mental illness. Iran J Psychiatry Behav Sci 2016;10(3):e1887.

[9] Abdool PS, Nirula L, Bonato S, et al. Simulation in undergraduate psychiatry: exploring the depth of learner engagement. Academic Psychiatry 2017;41(2):251-61.

[10] Ahmedani BK, Kubiak SP, Rios-Bedoya CF, et al. Willingness to treat drug dependence and depression: comparisons of future health professionals. Substance Abuse and Rehabilitation 2011;2011(2):43-51.

[11] Hankir AK, Northall A, Zaman R. Stigma and mental health challenges in medical students. BMJ Case Reports 2014;2014. pii: bcr2014205226.
[12] Roncero C, Egido A, Rodriguez-Cintas L, et al. Drug use among medical students: a review of the literature 19882013. Actas Esp Psiquiatr 2015;43(3):109-21.

[13] Gonçalves M, Moleiro C. Resultados de um programa piloto de desestigmatização de saúde mental juvenil. Revista Portuguesa de Saúde Pública, 2016;34(3):276-82.

[14] Telles-Correia D, Marques GJ, Gramaça J, et al. Stigma and attitudes towards psychiatric patients in Portuguese medical students. Acta Médica Portuguesa 2015;28(6):715-9.

[15] Chang S, Ong HL, Seow E, et al. Stigma towards mental illness among medical and nursing students in Singapore: a cross-sectional study. BMJ Open 2017;7(12): e018099.

[16] Fernandez A, Tan KA, Knaak S, et al. Effects of brief psychoeducational program on stigma in Malaysian preclinical medical students: a randomized controlled trial. Acad Psychiatry 2016;40(6):905-11.

[17] Gilaberte I. Failde I, Salazar A, et al. Attitude of 5th grade students of medicine towards mental health. Educ Med 2012;15:227-33.

[18] Magliano L, Read J, Patalano M, et al. Counteracting the stigma towards people with schizophrenia in the health field: a pilot experience in a sample of Italian medical students. Psychology, Society \& Education 2012;4(2):169-81.

[19] Slavin SJ, Schindler DL, Chibnall JT. Medical student mental health 3.0: improving student wellness through curricular changes. Academic Medicine: Journal of the Association of American Medical Colleges 2014;89(4):573-7.

[20] Kassam A, Glozier N, Leese M, et al. A controlled trial of mental illness related stigma training for medical students. BMC Medical Education 2011;11:51.

[21] Shen Y, Dong H, Fan X, et al. What can the medical education do for eliminating stigma and discrimination associated with mental illness among future doctors? Effect of clerkship training on Chinese students' attitudes. The International Journal of Psychiatry in Medicine 2014;47(3):241-54.

[22] Patten SB, Remillard A, Phillips L, et al. Effectiveness of contact-based education for reducing mental illnessrelated stigma in pharmacy students. BMC Medical Education 2012;12:120.

[23] Ogunsemi 00, Odusan 0, Olatawura MO. Stigmatising attitude of medical students towards a psychiatry label. Annals of General Psychiatry 2008;7(1):15.

[24] Stubbs A. Reducing mental illness stigma in health care students and professionals: a review of the literature. Australasian Psychiatry 2014;22(6):579-84.

[25] Ighodaro A, Stefanovics E, Makanjuola V, et al. An assessment of attitudes towards people with mental illness among medical students and physicians in Ibadan, Nigeria. Acad Psychiatry 2015;39(3):280-5.

[26] Sartorius N. Stigma: what can psychiatrists do about it? The Lancet 1998;352(9133):1058-9.

[27] Ücok A, Soygur H, Atakli C, et al. The impact of antistigma education on the attitudes of general practitioners regarding schizophrenia. Psychiatry and Clinical Neurosciences 2006;60(4):439-43. 
[28] Poreddi V, Thimmaiah R, Math SB. Attitudes toward people with mental illness among medical students. Journal of Neurosciences in Rural Practice 2015;6(3):349-54.

[29] Sandhu HS, Arora A, Brasch J, et al. Mental health stigma: explicit and implicit attitudes of Canadian undergraduate students, medical school students and psychiatrists. The Canadian Journal of Psychiatry 2019;64(3):209-17.

[30] Akhunzada WA, Abbas A, Akmal M, et al. Attitude of girls medical students towards psychiatry. KJMS 2014;7(2):302-8.

[31] James BO, Omoaregba JO, Okogbenin EO. Stigmatising attitudes towards persons with mental illness: a survey of medical students and interns from southern Nigeria. Mental Illness 2012;4(1):e8.
[32] Ungar T, Knaak S. The hidden medical logic of mental health stigma. Aust N Z J Psychiatry 2013;47(7):611-2.

[33] Lopez M, Laviana M, Fernandez L, et al. The fight against stigma and discrimination in mental health. A complex strategy based on the available information. Rev Asoc Esp Neuropsiq 2008;28(101):43-83.

[34] Fernando SM, Deane FP, McLeod HJ. Sri Lankan doctors' and medical undergraduates' attitudes towards mental illness. Soc Psychiatry Psychiatr Epidemiol 2010;45(7):733-9.

[35] Arbanas G. Adolescents' attitudes toward schizophrenia, depression and PTSD. J Psychosoc Nurs Ment Health Serv 2008;46(3):45-51. 